\title{
Bone Screw Manufacturing for Bone Reconstruction: An Application in Veterinary Orthopedics
}

\author{
Abedrabbo Faruk, MSc. ${ }^{1}$, Benavides Oscar, MV. ${ }^{2}$, Rojas Fabio, Dr. Eng Mec. ${ }^{1}$ \\ ${ }^{1}$ Universidad de los Andes, Colombia, af.abedrabbo@uniandes.edu.co, fa.rojas@uniandes.edu.co \\ ${ }^{2}$ Clínica Veterinaria Dover, Colombia, oscar@dover.com.co
}

\begin{abstract}
Currently, there are few studies on lyophilized bovine bone as a biomaterial for the manufacture of bone reconstruction implants [4] [8] [9] and these are usually focused on their manufacture, sterilization or mechanical comparison with other materials. The implants manufactured in this biomaterial have a main advantage over implants made of other materials, osteoinduction and osteoconduction, which cause the complete regeneration of the implant, eliminating the need for a second surgery to remove them. The main objective of this research article was to design and implement a guide for the manufacturing of HA2.7 screw implants; this manufacturing line includes the steps of material preparation, machining, cleaning, packaging and sterilization. In order to verify each of these stages, cytotoxicity tests, analysis of implant textures, chemical analysis, dimensional analysis, reproducibility and repetitiveness analysis of the process, and surface roughness analysis were used until the implantation of the screw as a fixation of fasciae latae implants. The surgery is based on an extraarticular repair of the anterior cruciate ligament rupture in a dog, where the behaviour of the screw was observed as its osseointegration in time until the patient recovered.
\end{abstract}

Keywords-bovine bone; lyophilized bone; osseointegration; HA screw.

\section{INTRODUCTION}

Bone filling defects can be corrected using different types of materials like autograft, allograft and xenograft, which are commonly used [1] [2]. The xenograft is considered an alternative material for bone transplantation, but its healing capacity is lower when compared with autografts and allografts. It has been proven by geogenic bovine bone grafts in dogs that bone morphogenetic protein enhances the suitability of bone demineralization [3].

Bovine bone helps promote bone growth in a vertical direction, which is a current limitation of existing regenerative materials. The histological evaluation confirmed the new bone formation to include components, such as osteocytes and osteons, showing the effectiveness of the use of bone screws to provide an environment conducive to bone formation [4].

The screws derived from compact bovine bone show good results, similar to titanium interference screws. Therefore, products derived from xenogeneic bone should be further investigated [5]. One study compared the torsional stability of different self-piercing interference screws of bovine bone with conventional metallic polymer interference screws (Tutofix) which are bioabsorbable. This study concluded that bovine bone screws have a torsional stability that can be compared to interference screws (Tutofix.). The safety and in vivo performance of products derived from xenogeneic bone should be the focus of future research [6].
As can be seen in the literature, the properties of lyophilized bovine bone have been proven. In the same way, screws for bone reconstruction have been experimentally manufactured from this biomaterial, and for these advances, the main objective of this study was to design and implement a semiautomatic manufacturing line of HA2.7 screws, which includes the steps of material preparation, machining, cleaning, packaging and sterilization to obtain ready-to-use implants with good mechanical and medical characteristics. Those HA2.7 screws were used for the extraarticular repair of the anterior cruciate ligament rupture of a dog at the Dover Veterinary Clinic.

\section{METHODOLOGY}

\section{A. Description implant manufacturing}

Orthopedic screws HA2.7 were manufactured in a length of 15 [mm]. Standard ASTM F543-17 [7] was taken as reference as it describes the dimensional characteristics for orthopedic screw type HA and some of its features and mechanical tests. In Fig. 1, the measures for the thread profile of the screw are shown, a thread pitch $(\mathrm{P})$ of 1 [mm], a crest width of $0.1[\mathrm{~mm}] ; \mathrm{r} 4$ and $\mathrm{r} 5$ are the minimum radius to describe the thread profile, with values of $0.4[\mathrm{~mm}]$ and 0.2 $[\mathrm{mm}]$ respectively. The helix angle $(\alpha)$ is $35\left[^{\circ}\right]$ and the relief angle is $3\left[^{\circ}\right]$.

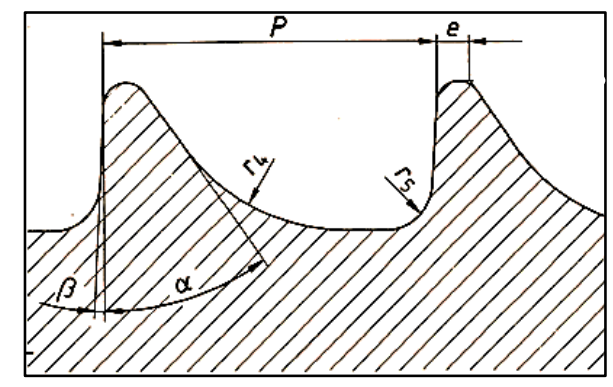

Fig. 1. HA thread profile, taken from the standard ASTM F543-17 [7].

\section{B. Implant machining}

The manufacture of the screws was performed in lyophilized bovine bone, in which tibia and femur bovine was used, since these deliver the greatest thickness of cortical bone. To obtain a raw material with the same dimensions and to ease handling and assembly, test specimens were prepared with pieces of bone and with the help of epoxy putty, obtaining specimens with a diameter of 16.8 [mm]. The

Digital Object Identifier (DOI):

http://dx.doi.org/10.18687/LACCEI2019.1.1.312

ISBN: 978-0-9993443-6-1 ISSN: 2414-6390

$17^{\text {th }}$ LACCEI International Multi-Conference for Engineering, Education, and Technology: "Industry, Innovation, And 1 Infrastructure for Sustainable Cities and Communities", 24-26 July 2019, Jamaica. 
manufacturing process is conducted in the $\mathrm{CNC}$ and the screws were completed in manual milling machine. For assembly of the raw material on both machines, a coupling glass type was manufactured which has the exact size of 16.8 [mm] of the raw material and allows the clamping of the jaws of the machine to be equally distributed all around the raw material.

Optimal parameters were obtained for the perfect manufacturing of the screws in the shortest possible time and without exceeding the temperature conditions of 40 degrees Celsius recommended in the scientific literature (Albrektsson and Sennerby), as this may compromise the osseointegration of the bone (Lundskog), all cited in the Doctoral thesis by Fabio Rojas [8]. Additionally, within the turning process it is required to manufacture the thread application saline $3 \%$ as cutting fluid, as this fluid is applied using an atomizer and quantified so that the approximate amount for these screws is 4.55 [ml]. Fig. 2 presents the shape of the lyophilized bone at the end of the turning process, and with the complete screw thread.

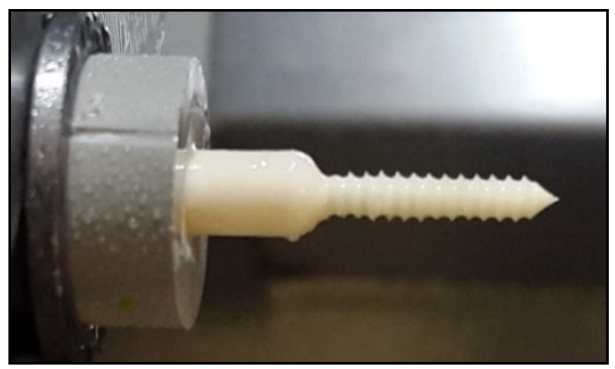

Fig. 2. Finishing the turning process.

The parameters for the machining of screws HA2.7 were established in 3000 [RPM] for the longitudinal and 660 [RPM] for threading, and tool speed of 1100 [RPM] was used for milling the head. For turning the raw material, a commercial insert used with reference VNGG -04-12 SGF1105 , which has a tip radius of 1.191 [mm]; this sharp radius prevents the blade to produce a fracture in the bone. To produce the threading, an HSS chisel sharpening tool with the profile described in Fig. 1 was used, extracted from standard ASTM F543-17 [7]. The finished hex-head screws were held in the router with a straight cutter rod $8[\mathrm{~mm}]$. At the end of the process of machining, the remaining material, which is inside the cup holding cut Fig. 3, shows that it is finished and ready for the next stages of the manufacturing process screw.

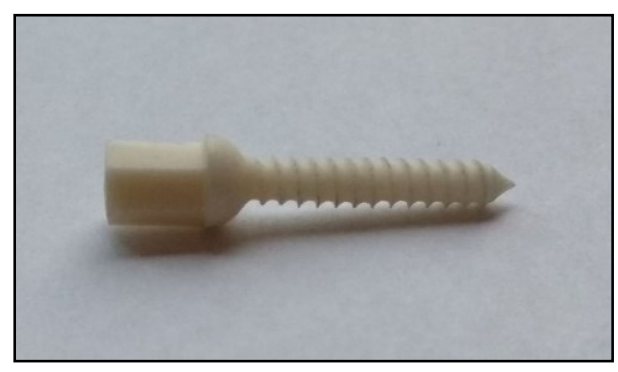

Fig. 3. Screw HA2.7x15 [mm].
Part of the advancement in the scientific literature was also to achieve a semi-automated process for the manufacturing of screws, as authors like P. Haje [9] and Volpon J. [10] have made screws, but experientially starting from a piece of bone and manual shaping machinery, which increases the time of the machining process. However, this project obtained a total time of approximately 30 minutes to manufacture each screw, 20 minutes to complete the turning of the implant and 10 minutes for the completion of the hex head screws. Therefore, the manufacturing process described in this article is the first to be achieved in Colombia and is ready to be industrialized.

\section{Cleaning, packaging and sterilization}

Once the entire batch of implants was obtained, it was required that they were sterilized before being used in animals. Before sterilizing the implants, they are cleaned and packaged in a clean room (sterile).

An ultrasonic shaker was used, and the disinfection of the implants was performed. Due to the machining process in the machine shop, and the machine shop itself, there could be foreign particles besides lyophilized bone particles, which deposits in the implant pores. Moreover, thanks to the ultrasonic agitator, particles of the HSS tool, which can become embedded in the implant by the cutting blade, are extracted. The implants were placed in the shaker in glass containers containing ethyl alcohol $96 \%$, producing the disinfection of the whole implant surface.

After stirring, the implants are extracted one by one with a sterile tool, as shown in Fig. 4. There are dried with compressed air, and once the implant is completely dry, it is introduced into sterilization envelopes.

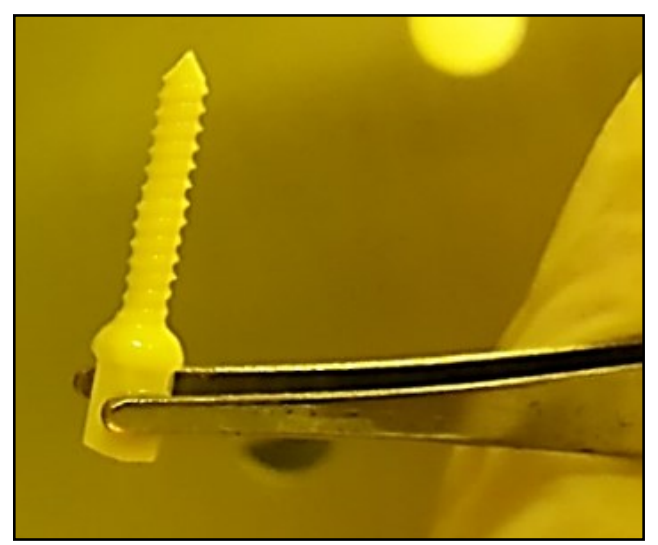

Fig. 4. Implantation extracted ultrasonic stirrer.

Sealed sterilization envelopes are sent. This specific product is sterilized with Gamma radiation. This technology operates on the principle of breaking DNA chains of microorganisms, so any microorganism is eliminated, or its development is inhibited. Thus, Colli Escherichia, Salmonella, Trichinella spiralis and other pathogenic microorganisms are removed from the implant to apply the proper dose of gamma radiation. For these implants'

$17^{\text {th }}$ LACCEI International Multi-Conference for Engineering, Education, and Technology: "Industry, Innovation, And Infrastructure for Sustainable Cities and Communities”, 24-26 July 2019, Jamaica. 
irradiation, 2 [megarads] were used based on the recommendations of the scientific literature, which indicates that it is enough to irradiate between 2 or 3 [megarads] to sterilize the screws, according to Fabio Rojas [8]. After 3 [megarads] the mechanical properties of bone are drastically affected according to Pelker, et al. [11]. In Fig. 5, it can be observed that the sterilized implant is ready for use.

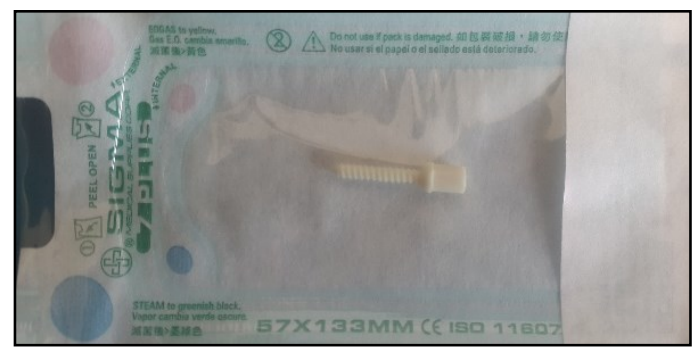

Fig. 5. Implant Gamma radiation sterilized.

\section{RESULTS AND DISCUSSION}

\section{A. Cytotoxicity test: MTT}

A variety of cytotoxic assays for determining toxic levels of a substance can be implemented, such as the evaluation of its effect on cell growth, viability, change in the size of the cell population, the change in biomass (total protein or total DNA) or in metabolic activity (DNA synthesis, RNA).

A chronic cytotoxicity study is conducted to evaluate the effect of a chemical agent over a prolonged exposure time. The MTT colorimetric technique permits the quick and easy assessment of the total cell mass in a cell culture. The method is based on the staining of cells with MTT solution and quantification, in a spectrophotometric microplate reader, the optical density (or absorbance) of the crystals in Formazan solution resulting from mitochondrial activation MTT living cells, as evidenced by Mossman [12] in 1983.

Cytotoxicity assays were performed at the Laboratory of Human Genetics at Universidad de Los Andes. Screws were available previously sterilized by gamma radiation in a centrifuge tube $15[\mathrm{ml}]$ and covered with $2[\mathrm{ml}]$ of Dulbecco's Modified Eagle Medium (DMEM) Fetal Bovine Serum (FBS). The screws were incubated in the medium at $37\left[{ }^{\circ} \mathrm{C}\right]$ in a humidified atmosphere with 5\% CO2 for 1, 2 and 7 days. After different periods of incubation, the medium was removed and used for cytotoxicity assays.

Cell viability was determined by MTT test Mossman [12]. Human Foreskin Fibroblast Cells were used: Human Foreskin Fibroblast (HFF-1-ATCCCRSCRC-1041 ${ }^{\mathrm{TM}}$ ), at a concentration of $2 \times 105$ [cells/ml] in 96-well microplate. HFF-1 cells were cultured in DMEM medium supplemented with 15\% FBS, 1\% Penicillin / Streptomycin and incubated at $37\left[{ }^{\circ} \mathrm{C}\right]$, in a humidified atmosphere with $5 \% \mathrm{CO} 2$.

The treatment was performed after cells reached confluence in the microplate. Cells were then incubated at 37 $\left[{ }^{\circ} \mathrm{C}\right]$ in a humidified atmosphere and 5\% CO2. After 24 hours,
$10[\mathrm{Pl}]$ of MTT $(5[\mathrm{mg} / \mathrm{ml}])$ were added to each culture and re-incubated for 2 hours.

After removing the medium, 100 [Pl] of dimethyl sulfoxide were added to dissolve the formazan crystals. The microplate was analyzed in a microplate reader (BioRad) at a wavelength of $595[\mathrm{~nm}]$ and $655[\mathrm{~nm}]$ reference. The results are presented as a percentage of live cells (viability) calculated from the absorbance of the negative control, taking the latter as $100 \%$. In addition, the percentage of cytotoxicity subtracting $100 \%$ viability value obtained for each treatment was calculated.

After exposure to 24-hour extracts of different days, it was observed that the average viability of HFF-1 cells does not decrease from $80 \%$ (Fig. 6A) being $90.09 \pm 4.84 \%$ for day 1 , from $98.88 \pm 0.56 \%$ for day 2 and $81.99 \pm 0.39 \%$ for day 7. According to ANOVA analysis, there were no significant differences between the control and the extract of day 7 (Fig. 6A).

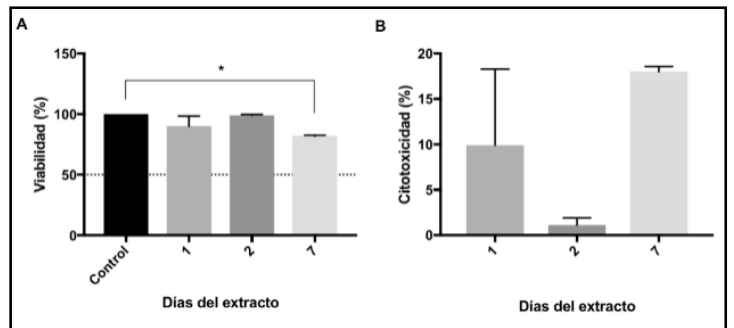

Fig. 6. Cytotoxic effect of water samples in HFF-1 cells. Percent viability (A) and cytotoxicity (B) after exposure to the extract of the screw after 1, 2, and 7 days incubation. ANOVA test one-way $(*) \mathrm{p}<0.05$.

\section{B. Texture analysis, thread shape and chemical composition of the screws}

The surface texture of the implants was analyzed using the surface texture pattern of lyophilized bone implant made in Brazil in the doctoral thesis "Fabricação de implantes ortopédicos a partir da usinagem de osso humano" by Fabio Rojas Mora [8], which was verified with several experiments that under these surface textures, the implant osseointegrates in human bone with excellent results. In the first comparison, similar results are seen between the implant made in Brazil with lyophilized human bone implants and 4 lyophilized bovine bone manufactured in Colombia. In Fig. 7, the comparison to $15 \mathrm{X}$ magnification in the electron microscope is observed.

The second comparison is only to check the thread profile. Although the implant made in Brazil is another magnification, the profile shape is the same. In addition, for four implants of lyophilizate bovine bone, the thread profile meets the standard measures since the profile depth is 0.4 [mm] and the pitch of the thread is 1 [mm]. Additionally, there are some crests of the thread that were broken; however, these do not exceed $100[\mu \mathrm{m}]$, so they are not considered critical to the screws, as can be seen in the scale photographs in Fig. 8, which has increased 80X under a microscope. 


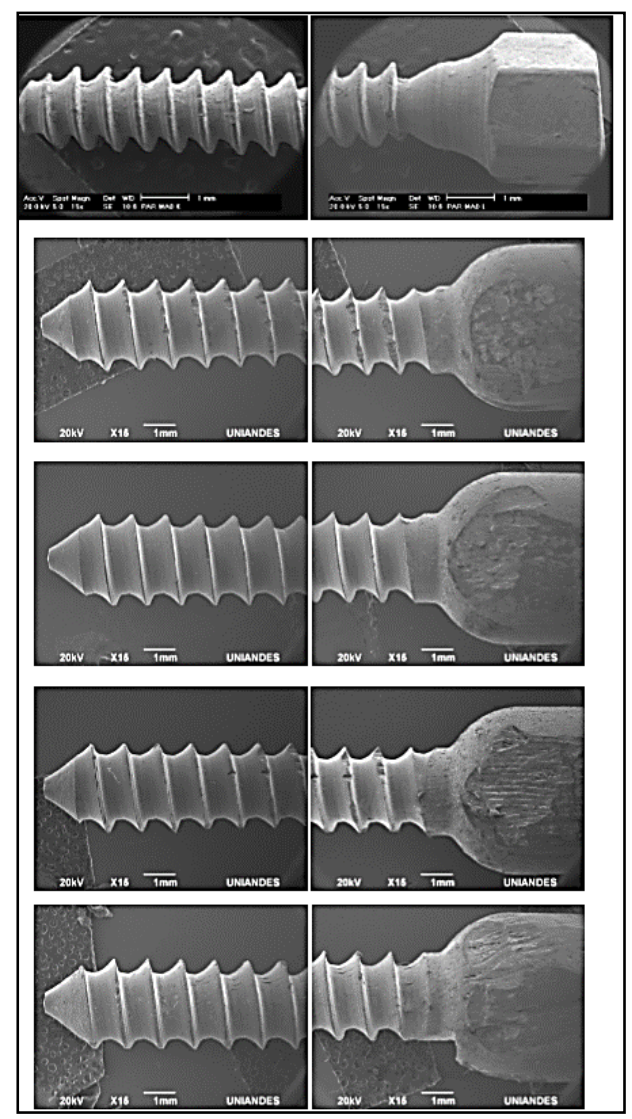

Fig. 7. General comparison implants, $15 \mathrm{X}$ magnification microscope.

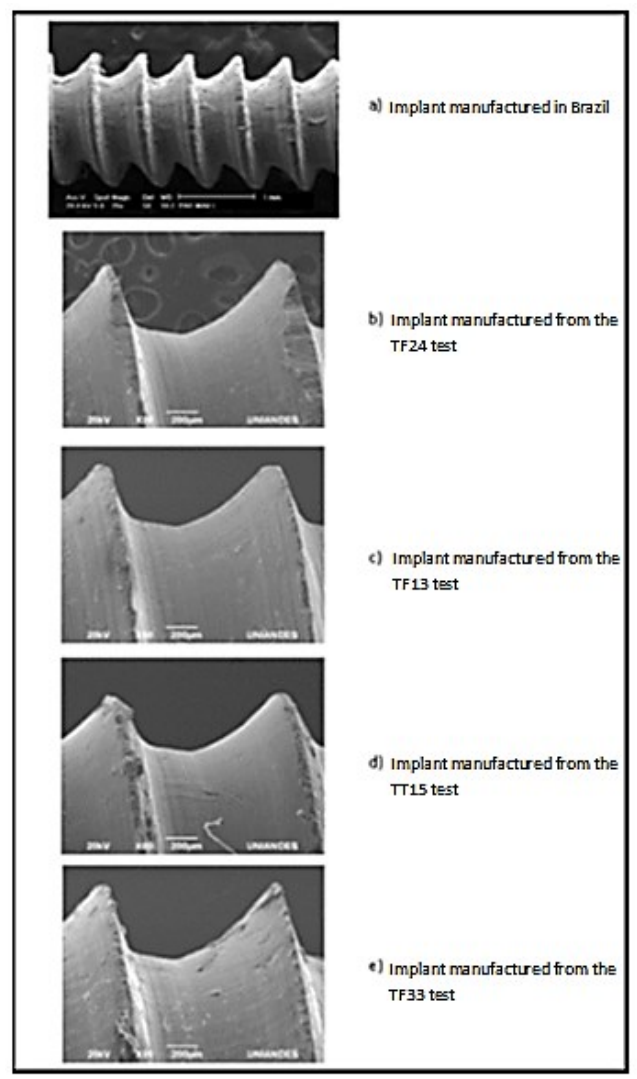

Fig. 8. Comparison of the thread profile and verification measures.

\section{Dimensional analysis screws HA2.7}

To validate the manufacturing system and screw measurements, a batch of 30 implants was produced, which was divided into two batches based on the manufacturing process. From these batches, an IT quality number was obtained for each dimension, based on ISO 286-2: 2010 [13].

Mean values and confidence intervals for the dimensions of inner diameter, outer diameter and thread pitch are shown in Table I, which were checked with the tolerances specified in the standard ASTM F543-17 [7].

TABLE I

DIMENSIONAL ANALYSIS BATCH OF IMPLANTS. External diameter of the implants [mm] Number of measures 180 \begin{tabular}{l|l}
\hline Average measurement & 2,678
\end{tabular} Standard deviation $\quad 0,035$ \begin{tabular}{l|l} 
Confidence interval $95 \%$ & $2.678 \pm 0.069$
\end{tabular} IT Number IT12 Inner diameter of the implants [mm] \begin{tabular}{l|l} 
Number of measures & 180
\end{tabular} \begin{tabular}{l|l} 
Average measurement & 1,922
\end{tabular} Standard deviation $\quad 0,031$ \begin{tabular}{l|r} 
Confidence interval 95\% & $1.922 \pm 0.061$
\end{tabular} IT Number IT12 Thread pitch of implants [mm] Number of measures Average measurement Standard deviation Confidence interval 95\% 180 0,999 0,022 $0.999 \pm 0.022$

The confidence interval for the outer diameter is within the tolerance of ASTM F543-17 [7], and it can be ensured that if the confidence interval at $99 \%$ of the data is expanded, the tolerances are satisfied. This measure is centered, and its deflection barely reaches $35[\mu \mathrm{m}]$. When checking the inside diameter of the thread, this is not within the tolerances specified in the standard; however, if the confidence interval is analyzed, it is lower in order of magnitude than the specified tolerance. Therefore, a problem of accuracy is evident, but not in precision, and accuracy is a problem that can be corrected without major problems in $\mathrm{G}$ code at the time of manufacturing to meet the tolerances specified in the following batches. Finally, by analyzing the pitch of the thread, the standard does not specify tolerances for this measurement; however, this measure had a mean of 0.999 $[\mathrm{mm}]$ and a standard deviation of only $22[\mu \mathrm{m}]$. It can be seen as an ideal manufacturing process variation since the measure is very central.

\section{Analysis of repeatability and reproducibility $(R \& R)$ machining}

The analysis of repeatability and reproducibility is to verify the machining process, particularly the variation that the machine could have (repetitiveness) and variation that the batches could have (reproducibility), either by the operator or by other factors. For this analysis, a single measure of the

$17^{\text {th }}$ LACCEI International Multi-Conference for Engineering, Education, and Technology: "Industry, Innovation, And Infrastructure for Sustainable Cities and Communities", 24-26 July 2019, Jamaica. 
implant was used, considering the outer diameter as the main measure of the implant.

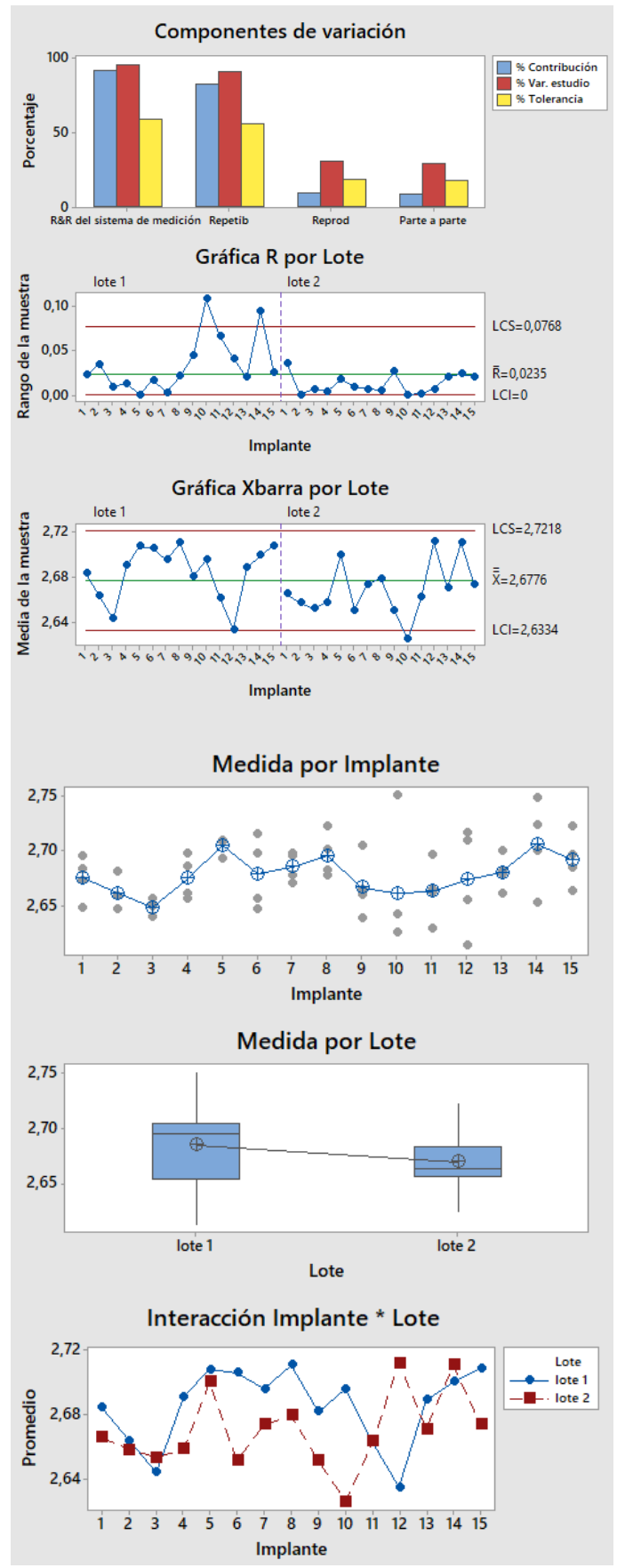

Fig. 13. Analysis results R\&R.

It should be noted that this analysis is carried out with a reliability rate of $99 \%$, this means that confidence intervals are based on 3 standard deviations. Table II shows that for tolerance, the study has a variation of $59.01 \%$ which is high. Within this percentage, $55.9 \%$ is clearly product repeatability of the machine, in this case the CNC lathe, which means that in the process batches of implants with the same dimensions are not being obtained, which is easier to show in Fig. 13. The batch control sheet shows that the batch 1 has implants protruding from the specification limits of tolerance, while batch 2 has all implants within the limits. There is a variation between the batches by influence of machine parameters such as materials, inserts, chisels, etc. Here it is evident that the buckling of the bone has an effect on the measurements of the implants, although it is small enough to hold to the tolerances specified in the standard ASTM F543-17 [7].

TABLE II

R \& R EVALUATION OF THE MANUFACTURING SYSTEM.

\begin{tabular}{|c|c|c|c|c|}
\hline Source & $\begin{array}{c}\text { Desv. Est. } \\
\text { (DE) }\end{array}$ & $\begin{array}{c}\text { Var. study (3 } \\
\times \text { DE) }\end{array}$ & $\begin{array}{c}\text { \% Var. } \\
\text { study (\% } \\
\text { VE) }\end{array}$ & $\begin{array}{c}\text { \% Tolerance } \\
\text { (VE / Toler) }\end{array}$ \\
\hline Gage R\&R Total & 0.0295 & 0.0885 & 95.71 & 59.01 \\
\hline Repeatability & 0.0279 & 0.0838 & 90.67 & 55.90 \\
\hline Reproducibility & 0.0094 & 0.0283 & 30.66 & 18.90 \\
\hline Batch & 0.0094 & 0.0283 & 30.66 & 18.90 \\
\hline Portion & 0.0089 & 0.0267 & 28.97 & 17.86 \\
\hline Total change & 0.0308 & 0.0924 & 100.00 & 61.65 \\
\hline \multicolumn{4}{|c|}{ Number of different categories $=1$} \\
\end{tabular}

Furthermore, it verified that the percentage contribution of reproducibility is less than $20 \%$, which means that the process is acceptable under the criteria of Gutiérrez Pulido and Vara Salazar [14]. The manufacturing system can be reproduced by any operator following the basic requirements of the process. In addition, there is no influence as the operator places the cutting fluid or makes handling parts.

\section{E. Analysis of the surface roughness of the screws HA2.7}

Similarly, we have characterized the product obtained based on the surface roughness, thus verifying the manufacturing process. The roughness of HA2.7×15 [mm] screws is taken in 3 different points: first on the thread, on the last turn of the thread and the screw head. Roughness is also a biological factor, which at the molecular level affects the way the cells attach to surfaces according to Hinojosa Rivera and Reyes Melo [15]. Therefore, it is important to control this factor in the manufacturing process. In Table III, the results of the weighted average roughness ( $\mathrm{Ra}$ ) and standard deviations (RMS) is observed in short.

TABLE III

RESULTS WEIGHTED ROUGHNESS

\begin{tabular}{|c|c|}
\hline Weighted average & $0.26[\mu \mathrm{m}]$ \\
\hline Weighted standard deviation & $0.16[\mu \mathrm{m}]$ \\
\hline
\end{tabular}

To compare the roughness measurement obtained from the implants, the value of average roughness parameter $(\mathrm{Ra})$ was compared with the same parameter from some commercial implants used nowadays, which are produced by the following materials: pure titanium, titanium alloys- $6 \%$ Aluminum-7\% niobium, and stainless steel. This comparison is shown in Table IV and is based on the application, the company that manufactures it and the material and surface finish, it was compared to both dental implants as orthopedic implants. Therefore, under these conditions, the implant will

$17^{\text {th }}$ LACCEI International Multi-Conference for Engineering, Education, and Technology: "Industry, Innovation, And Infrastructure for Sustainable Cities and Communities”, 24-26 July 2019, Jamaica. 
osseointegrate and there will be no rejection due to surface roughness.

As seen in Table IV, the implants made in this study have a very similar roughness to machined Defcon titanium implants, Synthes Titanium and alloyed Titanium implants, both electro-polished, which leads to the conclusion that the roughness obtained on the implants made of lyophilized bovine bone is within the range used by commercial implants, so there should be no rejection of these by the patient due to the roughness obtained.

TABLE IV

COMPARISON OF ROUGHNESS WITH OTHER IMPLANTS SCIENTIFIC LITERATURE.

\begin{tabular}{|c|c|}
\hline \multicolumn{2}{|l|}{ Implants Roughness } \\
\hline $\begin{array}{l}\text { Pure titanium dental implants Defcon TSA }{ }^{\circledR} \\
\text { machining without surface treatment }[16] \text {. }\end{array}$ & $0.37 \pm 0.03[\mu \mathrm{m}]$ \\
\hline $\begin{array}{l}\text { Pure titanium dental implants Defcon TSA }{ }^{\circledR} \\
\text { Subjected to acid etching, comprising etching of } \\
\text { the titanium surface with a hydrofluoric acid } \\
\text { solution, followed by passivation with a solution } \\
\text { of hydrofluoric and nitric acid according to ASTM } \\
\text { standard F86 [16]. }\end{array}$ & $1.06 \pm 0.05[\mu \mathrm{m}]$ \\
\hline $\begin{array}{l}\text { Pure titanium dental implants Defcon Avanblast } \\
\text { TSA }{ }^{\circledR} \text { subjected to a surface treatment in two } \\
\text { phases. In the first phase, following a } \\
\text { homogenization process tensions, etching the } \\
\text { surface of the implant with a solution of sulfuric } \\
\text { and hydrofluoric acid at elevated temperature was } \\
\text { applied. In the second phase, we proceeded to } \\
\text { subjecting the implant to a heat treatment furnace } \\
{[16] \text {. }}\end{array}$ & $1.23 \pm 0.11[\mu \mathrm{m}]$ \\
\hline $\begin{array}{l}\text { Orthopedic implants for cortical bone (ISO } \\
\text { 5835: 1991), Synthes }{ }^{\circledR} \text { Stainless Steel [17]. }\end{array}$ & $0.23 \pm 0.13[\mu \mathrm{m}]$ \\
\hline $\begin{array}{l}\text { Orthopedic implants for cortical bone (ISO } \\
\text { 5835: 1991), Synthes } ® \text { pure titanium micro- } \\
\text { roughened surface[17]. }\end{array}$ & $0.72 \pm 0.1[\mu \mathrm{m}]$ \\
\hline $\begin{array}{l}\text { Orthopedic implants for cortical bone (ISO } \\
\text { 5835: 1991), Synthes } ® \text { Titanium-6 Aluminum- } \\
7 \% \text { niobium } \% \text { micro-roughened surface }[17] \text {. }\end{array}$ & $1.04 \pm 0.15[\mu \mathrm{m}]$ \\
\hline $\begin{array}{l}\text { Orthopedic implants for cortical bone (ISO } \\
\text { 5835: 1991), Synthes }{ }^{\circledR} \text { pure titanium surface } \\
\text { polished electro [17]. }\end{array}$ & $0.09 \pm 0.01[\mu \mathrm{m}]$ \\
\hline $\begin{array}{l}\text { Orthopedic implants for cortical bone (ISO } \\
\text { 5835: } 1991) \text {, Synthes } ® \text { Titanium-6 Aluminum- } \\
\text { 7\% niobium } \% \text { electro-polished surface }[17] \text {. }\end{array}$ & $0.27 \pm 0.03[\mu \mathrm{m}]$ \\
\hline $\begin{array}{l}\text { Orthopedic implants for cortical bone (ISO } \\
\text { 5835: 1991), lyophilized bovine bone Made [17]. }\end{array}$ & $0.26 \pm 0.16[\mu \mathrm{m}]$ \\
\hline
\end{tabular}

\section{F. Osseointegration test under veterinary orthopedics}

The behavior of the screws was verified in a veterinary application. A screw was used as part of the fixing fasciae latae implant, for extraarticular repair of a rupture in the cruciate ligament in a dog. In this test, the behavior of the screw was checked against a real medical condition, and how it is osseointegrated with the animal bone after a period of time past the surgery in which the animal is fully recovered.

In Fig. 14 it can be observed that the radiograph taken after the surgery of the animal, clearly shows the screw on the proximal tibia of the dog. This screw serves as a clamp of the fasciae latae,

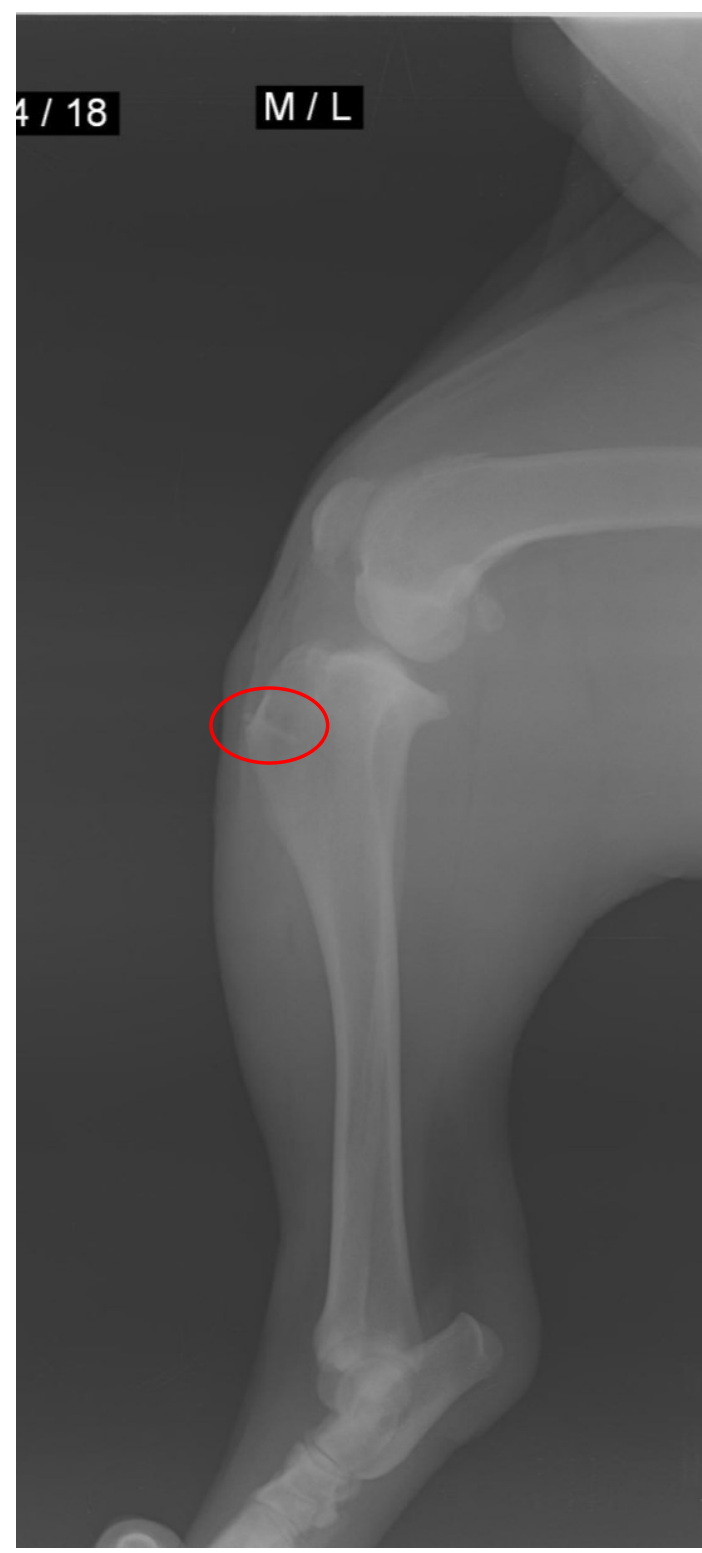

Fig. 14. Radiographic after surgery.

After 30 days of surgery, a second radiograph was taken, which is observed in Fig. 15, where it is not possible to distinguish the whole shape of the screw, only the portion protruding from the bone. This no longer has a defined shape, and it means that the screw is already formed in bone callus. In a qualitative definition, it is observed that the screw is osseointegrated, and since there is no difference between bone and screw, it means that the bone of the animal regenerated completely, and the screw is osseointegrated. This proves the properties of osteoinduction and osteoconduction of the manufactured implants.

$17^{\text {th }}$ LACCEI International Multi-Conference for Engineering, Education, and Technology: "Industry, Innovation, And Infrastructure for Sustainable Cities and Communities", 24-26 July 2019, Jamaica. 


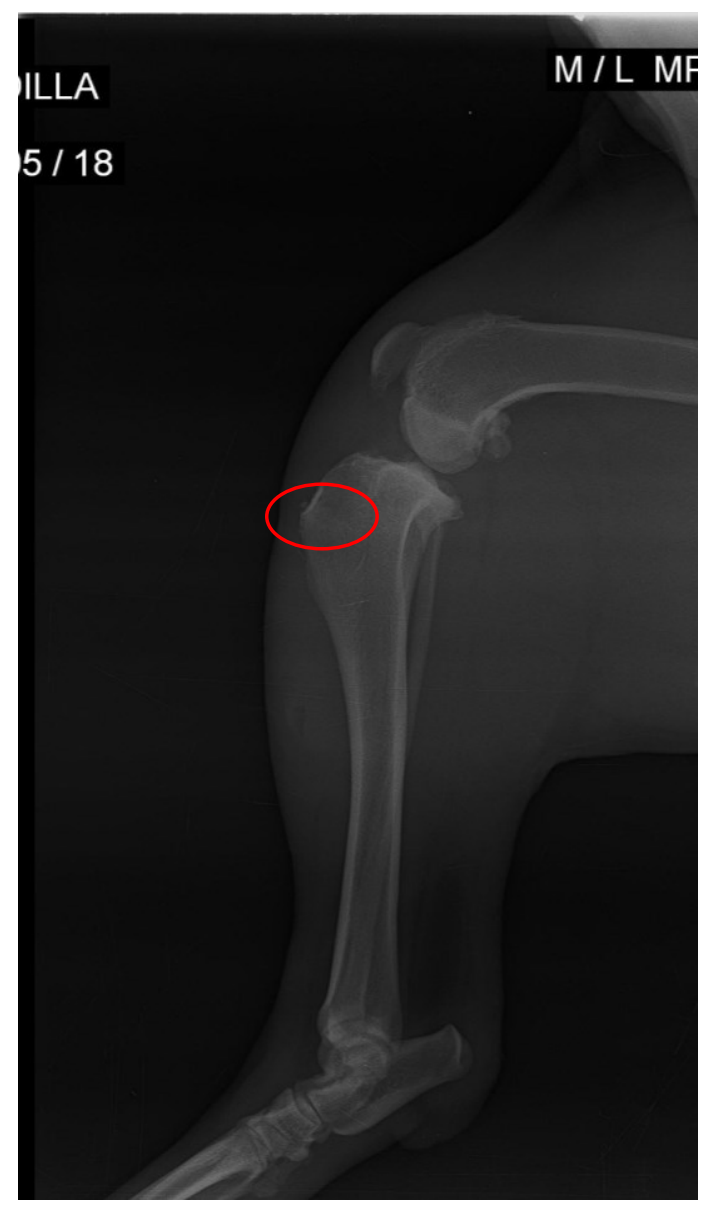

Fig. 15. Radiography within 30 days of surgery.

\section{CONCLUSIONS}

From the results obtained in this investigation, it is concluded that it is possible to manufacture screw implants type HA2.7 by machining with dimensional tolerances specified in the standard ASTM F543-17 [7] and with similar superficial roughness of implants with other materials. Cleaning, packaging, and sterilization process are viable, as demonstrated by cytotoxicity tests and osseointegration tests. A screw was used to repair the anterior cruciate ligament rupture on a dog, proving the application of these implants in veterinary orthopedics. With the progress made in this article, researchers are invited to continue researching implant technology in order to get more applications in orthopedics and dentistry for animals.

\section{REFERENCES}

[1] Finkemeier CG (2002) Bone-grafting and bone-graft substitutes. Am J Bone Joint Surg 84A: 454-464.

[2] Hagen A, Gorenoi V, Schönermark MP (2012) Bone graft substitutes for the treatment of traumatic fractures of the extremities. GMS Health Technol Assess. doi: 10.3205 / hta000102.

[3] Tuominen, T., Jämsä, T., Tuukkanen, J., Marttinen, A., Lindholm, T., \& Jalovaara, P. (2001). Bovine bone implant With bovine bone morphogenetic protein in ulnar defect healing to canine. International Orthopedics: Official Journal of the Société Internationale de
Chirurgie orthopedique Et Traumatologie (sicot), 25 (1), 5-8. doi: 10.1007 / s002640000208.

[4] Bianchini MA, MA Pontual, Bez L, Benfatti CA, Boabaid F, Somerman MJ, \& Magini RS. (2013). The use of bovine bone screws to Promote formation using a tibia model in dogs. Oral Surgery, Oral Medicine, Oral Pathology Oral Radiology And, 116 (4), E215-20. doi: $10.1016 /$ j.oooo.2011.12.018.

[5] Eph T, Bauer J, Herdrich S, Gotzen L, El-Zayat BF, Schmitt J, \& Schofer MD. (2010). Comparison Between bovine bone and titanium interference screws for fixation in ACL reconstruction implant: a biomechanical study. Archives of Orthopedic and Trauma Surgery, 130 (8), 993-9. doi: 10.1007 / s00402-010-1052-0.

[6] Bauer, J., Eph, T., Herdrich, S., Gotzen, L., El-Zayat, BF, Schmitt, J., Schofer, DM (2010). Torsional stability of interference from bovine bone screws derived - to biomechanical study. BMC Musculoskeletal Disorders, 11 (1), 1-8. doi:10.1186/1471-2474-1182.

[7] ASTM F543-17 Standard Specification and Test Methods for Metallic Medical Bone Screws, West Conshohocken, PA, 2017. doi: https: //doi-org.ezproxy.uniandes.edu.co: 8443 / 10.1520 / F0543-17.

[8] Rojas Mora, F. (2000). FABRICACAO Orthopedic implants from human osso gives usinagem. doctoral thesis. Federal University of Santa Catarina.

doi:http://repositorio.ufsc.br/xmlui/handle/123456789/79363.

[9] D. Haje, Volpon J. (2006). Parafusos desenvolvimento of bovine osso: Method usinagem e estudo metrological com profile projetor bovine bone screws development: Machining method and metrological study With projector profile. Acta Ortopédica Brasileira, 14 (2), 87-91. doi:10.1590/s1413-78522006000200006.

[10] Haje, D. Volpon, J., Moro, C. (2009). Bovine bone screws: Metrology and effects of chemical processing and ethylene oxide sterilization on bone surface and mechanical properties. Journal of Biomaterials Application, 23 (5), 453-471.

[11] Pelker, Richard R., Friedlaender, Gary E. and Markham, Thomas C., Biomechanical Properties of Bone Allografts, Clinical Orthopedics and Related Research, 174, pp.54-57, April 1983.

[12] Mosmann, T. (1983) Rapid colorimetric assay for cellular growth and survival - application to proliferation and cytotoxicity assays. J. Immunol. Methods, 65, 55.63.

[13] ISO 286-2: 2010- Geometrical Product Specifications (GPS) system code for tolerances on linear sizes - Part 2: Tables of standard tolerance classes and limit deviations for holes and shafts. (2010). doi: https: //www.iso.org/obp/ui/\#iso: std: iso: 286: -2: ed-2: v1: em.

[14] Pulido Gutiérrez, H. and Vara Salazar, R. (2009). Statistical Quality Control and Six Sigma. 2nd ed. Federal District: McGraw-Hill.

[15] Hinojosa Rivera, M. and Reyes Melo, M. (2001). The surface roughness: Topometry. Engineering, IV (11), pp.27-33.

[16] Saban García, F., \& Rodriguez Rius, D. (2005). Physicochemical surface 9 dental implants with 3 different surface treatments. Oral Medicine, Oral Pathology and Oral Surgery (ed. Print), 10 (1), pp.4857.

[17] Pearce, A., Pearce, S., Schwieger, K., Milz, S., Schneider, E., Archer, C. and Richards, R. (2008). Effect of surface topography on removal of cortical bone screws in a novel model sheep. Journal of Orthopedic Research, 26 (10), pp.1377-1383. doi: 10.1002 / jor.20665.

$17^{\text {th }}$ LACCEI International Multi-Conference for Engineering, Education, and Technology: "Industry, Innovation, And Infrastructure for Sustainable Cities and Communities", 24-26 July 2019, Jamaica. 